\title{
MAKING THE MOST OF PRE-CLASS ASSIGNMENTS
}

\author{
Pablo Ballesteros-Pérez ${ }^{1}$, M. Carmen González-Cruz ${ }^{2}$, Adrian Tagg ${ }^{1}$, \\ Daniel Mora-Melià ${ }^{3}$ \\ ${ }^{1}$ University of Reading (UNITED KINGDOM) \\ ${ }^{2}$ Universitat Politècnica de València (SPAIN) \\ ${ }^{3}$ Universidad de Talca (CHILE)
}

\begin{abstract}
When teaching a course, the lecturer or teaching instructor may need that students read some material before coming to the next face-to-face session. Counting on students that have done their assignments and that have done them well, allows the lecturer to make quicker and deeper progress in the contact session. It also raises motivation and allows devoting more time to hands-on practice rather than lecturing, the latter being a method that has proven to reach very low retention levels among students.
\end{abstract}

However, getting the students to read and work on their assignments is easier said than done, and many lecturers feel compelled to set in-class tests and quizzes in order to lure the students to fulfil their homework tasks. However, in-class tests and quizzes are also time-expensive, both inside and outside the classroom, and they are not exempt of other disadvantages.

In this paper, we will go over some methods that Teaching and Learning research has found to promote high levels of student understanding and retention, but that are generally too time-consuming to implement them on a regular basis. Also, drawing on the authors' experience and other research studies, we will present some alternative methods that are almost as effective as the former but require significantly lower time resources.

Keywords: pre-class assignments, self-assessment, Just-in-Time Teaching (JiTT), Guided reciprocal peer questioning, concept map drawing.

\section{INTRODUCTION}

Devoting a significant amount of time to lecturing in a classroom does not promote high-level understanding, nor long-term retention [1,2]. Instead, many good lecturers try to devote most of the 'contact' time with students trying to get them to do useful things, hands-on practice normally. Indeed, when a lecturer or instructor adopts a student/learner-centred approach [3], he/she will probably not be able to spend much time conveying information, so that he/she allows his/her students to practice themselves instead of listening to him/her talk.

However, generally it is not uncommon that lecturers need their students to know 'a few key/basic things' before they come to class, otherwise they will not be able to work on hardly anything. This is particularly important when they need to acquire some kind of 'factual' information [4] and generally, the way they ensure that their students will be prepared is by asking them to work on assignments before coming to the next class. This way, they can read, understand and reflect on some issues that will be addressed in the next session.

The common problem of an approach that involves a lecturer asking his/her students to read some pages before coming to the next class is that, in most occasions, very few decide to pay attention and read those pages. The vast majority of students act either as if they had never looked (presumably on purpose) at the assignment or, worse, they act as if they did not even remember that there was an assignment to read!

The normal consequence for first-time lecturers is that, when they realise that their students have not worked on what he/she asked them to, they feel as if they have no option but to squeeze an unplanned lecture about what they should have read at home. More experienced lecturers, on the other hand, being well aware of the generally low average student's willingness to work at home unless there is some 'carrot', might decide to include short tests or quizzes at the beginning of his/her classes. With these tests, many students will surely feel more compelled to devote some time to the instructor's assignments and will eventually come more prepared to the next session. 
Indeed the second approach seems to be the norm for many lecturers nowadays when they want their students to do something: scare them with having to sit for a 'test'. Since the students require motivation, the 'threat' of a test allows us to have some leverage on them. The latter, nonetheless, it is not exempt of disadvantages.

There are some alternatives to the use of tests for 'inviting' (and achieving that) our students read and work in a homework assignment before we see them again in class. This will be precisely, the aim of the current paper. In order to fulfil that objective, this paper will be organised as follows. First, we will go provide the context to the following research questions: Why pre-class assignments are (sometimes) important and how can we promote that students engage with them. Then we will identify a couple of approaches that are not known to work according to researchers, but that are usually not adopted by teaching practitioners due to their time-consuming nature. Thirdly, we will propose a series of habits and methods that do the trick, but that are not as time consuming. Finally, we will provide some comments on the contribution to the mark that pre-class assignments should have on the overall course mark. A conclusions section will gather and summarise the most important findings.

\section{BACKGROUND}

Even before a lecturer sets some homework for his/her students, Felder and Brent [5] propose to reflect on three essential questions about pre-class assignments:

- How important is it to get your students to read before the next class?

- If it is important, how can you get them to do it?

- If the students are presumably literate to have reached your module, why are so many of them apparently incapable of understanding what you asked them to read?

The first question presents an interesting a first point to reflect upon: 'Do I really need my students to spend time reading this?'. Nowadays, students have multiple commitments, not only from your subject, but from many more, which normally clash between them. The students will normally prioritise the most relevant and/or urgent. So, the first question forces the lecturer to think whether giving his/her students homework to do as a 'habit' can be keeping them from devoting real 'quality' time, when the pre-class assignments become really important to you or their understanding. If you 'always' give them things to do at home 'by default', whenever they have other important submissions, they will prioritise those over yours, as quite probably the contribution to the final mark in your module by skipping one assignment will be low.

Also in this vein, sometimes, instead of giving homework, it is more productive to give a short 10'lecture and then start working on the subject right afterwards. The students come fresher and they can make an effort when you need them to. To sum it up, overload your students with pre-class assignments every week is probably not the best idea, 'pick your battles wisely'.

The second question from the list above ('how can you get them to do it?') follows the first when a lecturer considers their students really need to come prepared before making the most of their next class. How to answer this question is not evident at all, indeed, many lecturers opt for raising awareness on an impending, maybe with open date, test, so that the students have no choice but to 'study', which may (or may be not) the same as you wanted them to do. However, in order to answer this question properly, we will link it to the third on the list: 'Why my students can't/don't/won't read?'

First, every instructor knows that there are always some students who are lazy. For those, the most likely answer to the former question is that they can ignore the reading because they think there will be no consequences. Indeed, they might have been doing it for quite a while, so why will this module be different?

Now, however, we can assume that we have lured them to read with a looming test threat and that we might have gained some leverage on them. OK, they are reading now, but they are probably reading having in mind that they will have to take a short test which will counting 'something' towards their mark at the beginning of the lecturer's classes. Unexpectedly however for most experienced lecturers, the instructor senses anyway that his/her students are not understanding properly what they were asked to read. It is likely that they have not devoted enough time to read because they are lazy, but the proportion of students who do not seem to understand properly the reading material generally seems too high. What is wrong then? And what can it be done to overcome this problem. 


\section{ALTERNATIVE METHODS}

\subsection{What works, but we do not (generally) have time to implement}

It has been well known for a long time by teaching and learning researchers that the most effective assignments require students to work through interactive (online) tutorials, where multimedia presentations include questions and exercises [6].

Not that effective, but still useful, are well-constructed screencasts with lots of visual content, examples and demonstrations [7]. The idea is that if the students go through those assignments at home, we could devote our (generally short) classroom time to build on that material and even, for instance, flip the classroom [8] devoting the scarce contact time to problem-solving exercises.

The obvious problem is that preparing these 'multimedia' presentations take an awful amount of time, normally more than we have, and almost always more than we want to spend. Should a lecturer keep creating this material at small doses, it will take him/her years to cover most of your course contents (a moment in which he/she might not be teaching the same subject or course anymore!). Then, what many instructors do is to assign text book readings or hand-outs from text books to introduce new material, but, from the authors' viewpoint, this is generally unproductive, or rather not productive enough.

A fact is that most academic texts are generally dense, dry and difficult to decipher to most students [9]. To get anything but vague ideas the average student needs to read the text books with painstaking care and most of the students just do not find worth the effort. Being rational people, once they find their text incomprehensible, up to $70 \%$ of them just decide to ignore it [10].

However, at the same time, it is clear that a lecturer cannot give up on his/her students to read because, as future professionals, they are going to need to know how to get information from documents all the time [11]. Then, how is it possible to propose pre-class assignments and readings that are both feasible and relevant?

\subsection{What also works and we (might) do have time to implement}

Fortunately, there are some alternative methods to the optimum solutions (e.g. [6,7]) that are not as time-consuming, and almost as effective. Many of them are not new either, but certainly they are not commonly implemented in the classroom, at least not in STEM where the authors develop their teaching practice.

But before going over the details of these methods, we recommend to adhere to these good habits:

- Shorten the reading material and only ask for the essentials.

If it is not clearly linked to my Intended Learning Outcomes (ILOs), then take it off, but suggest it for those who want (and can) spend more time going deeper.

This practice shows having empathy for your students: 'my students have other modules to take care of, not just mine'.

- Always include online quizzes/tests with the assignments.

First, note that it has been said 'online', not 'in-class' tests. The problem with the latter, despite they can accomplish their primary objective (getting the student to read the assignments), is that they take time at the beginning of the class while handing them out, letting the students answer them, collecting them and, out of class, time to mark them. Hence, the feedback is not even immediate, not for the lecturer, nor for them.

Our experience is that it is impossible to spend less than $10 \%$ of the class time on this, and generally it will take from $15 \%$ to $20 \%$, which is a lot of time, and generally for questions that try to be 'objective' so that we can minimise the marking time.

That is, in the end, those in-classroom quizzes just measure low-level factual information [5] and, if this is going to be the case anyway, why take that time from the classroom time? What can a lecturer do then? In this regard, three feasible alternatives are generally available to make the most of online tests: 
$\circ$ Self-tests.

With current learning management systems like Blackboard ${ }^{\circledR}$ or online instant assessment applications like Socrative $\AA$, nowadays it is very easy to include extra information in the quizzes so as to provide them with affirmation or corrective feedback on the spot.

More advantages of these tools are that students can also try again until they get a full set of correct answers, while I, as a lecturer, I just need to prepare the questions and answers (as I would do anyway in paper-based tests) but now I just need to check who of my students have taken the test and who don't.

Another advantage is that, since the students feel sometimes inclined to copy the answers from each other, a very effective solution is to create a set of three times more questions that the ones that each student will received in one round. The test management software will then be asked to randomise each student's test with a (different) subset of questions. That way, they need to be very organised to copy from each other, which in the end will quite probably be more time-consuming than reading the assignment instead.

○ Just-in-time teaching (JiTT) [12].

Sometimes, the lecturer wants to include (long) open questions, not just multiple-option or short answer questions. In those occasions, one option is to let the students submit their answers (via Socrative ${ }^{\circledR}$, for instance) until the evening before the next session takes place. That way it is possible to tailor the classroom session to address specific problematic points. This alternative is quite powerful, but not for all classes of course, since it might be timedemanding at times. Also, it has been researched [12] that open-question tests work better with students who are already used to take self-tests on a regular basis, otherwise the chances of cheating the system are higher.

- Students generate their own questions about the readings and submit them to the lecturer beforehand $[13,14]$.

It is an alternative, or rather the next step, to the previous JiTT approach. The advantage is that the students' questions can be used for in-class activities. Also, the students feel more relaxed towards reading the assignment material (as they are the ones asking the questions) whereas the lecturer can give marking points anyway to those asking the best questions.

But there are more approaches that can promote pre-class (reading) assignments to work better. These are another two:

- Guided reciprocal peer questioning [15].

This approach is very useful when the readings have substantial conceptual content and the lecturer also has a little time to spare at the beginning of the class. Indeed, one of the advantages is that it can replace to a certain extent the lecture that might be necessary when a significant proportion (but never more than $50 \%$ ) of my students have not read the assignments.

The way it works is like this: the students make reading-relevant insertions in question stems such as 'What is the main idea of ?', 'What's the difference between and ? ? ', 'What if happens?','What assumptions were made in _?' and, one of the most powerful: 'What is the real-world application of ?'.

Basically, at the beginning of the class, the lecturer forms small groups and they try to answer some of these questions. Then, the whole class go over those which are more controversial.

The way they count toward the mark is by gathering the written questions and answers from different groups and/or taking note of the most relevant contributions. This technique, therefore, promotes critical thinking and also reading skills [16].

- Have the students draw concept maps [17]

Concept maps are block diagrams or flow charts that evidence interrelations among key ideas on a topic. Those who use concept maps generally do it sporadically, once in a course for example, because they usually take a lot of time to review. However, they promote deep understanding of information structures, so they are extraordinarily effective for hard-going topics in which it is more time-consuming not resort to them than implement them. 


\section{ON THE CONTRIBUTION TO THE MARK OF PRE-CLASS ASSIGNMENTS}

These are the approaches that Teaching and Learning research finds more effective for promoting a high level of participation in pre-class assignments. Also, the authors have tried them over the years and we can corroborate that they work nicely within and outside the class, while keeping the time devoted by the instructor to barely the same as proposing in-class test, but achieving significantly higher levels of understanding, retention and participation. Overall, these methods serve the purpose (prepare my students for the next class) while avoiding the lecturer the preparation of complex, timeconsuming extensive well-crafted online material.

A last note, however, is that a basic premise is that pre-class assignments must always count something towards the final mark, but not a lot due to the uncontrolled environment in which the students generally work on them. An overall contribution circa $5 \%$ to $20 \%$ has worked fine for the authors, otherwise students might not feel compelled to spend the required amount of time on them. However, the final contribution to the mark might vary for different contexts, so a trial and error might be more suitable for disciplines other than STEM.

\section{CONCLUSIONS}

When teaching a course, quite frequently, the lecturer or teaching instructor may need that his/her students read some material before coming to the next face-to-face session. Counting on students that have done their assignments and that have done them well, allows making quicker and deeper progress in the classroom. It also raises motivation and allows the lecturer to devote more time to hands-on practice rather than lecturing, the latter being a method that has proven to reach very low retention levels among students.

However, get the students to read and work on their assignments at home before coming to the next session is not evident. Indeed, many lecturers nowadays feel that they can only resort to in-class tests to address that apparent lack of commitment from the students, who are apparently too lazy or just forgetful about their homework duties.

In-class tests have some problems though. They usually take from $10 \%$ to $25 \%$ of class time, a time that is scarce per se. They also prevent from having timely feedback, as the tests are to be marked after the class has finished, so the session aim cannot be adapted until it is already late.

Based on Teaching and Learning research, as well as in the authors' experience as University lecturers, some alternative methods have been proposed.

First, always question oneself whether the pre-class assignment is essential and if not, don't ask the students to take it. If it is necessary, then, try to remove all the non-essential material so that the student's homework can really focus on the most relevant and that the reading material is really meaningful.

Second, always include online tests, so that the student can self-assess his/her progress and level of understanding before he/she goes back to class. Alternatively, Just-in-Time Teaching (JiTT) as well as having the students ask questions themselves and submit them until the evening before the next faceto-face session are also powerful approaches to promote higher student engagement and retention levels.

Third, once students are back in class, another two useful techniques for capitalising on what the students have developed and worked at home are Guided reciprocal peer questioning and Concept maps drawing. Being the former is particularly useful when the readings have substantial conceptual content, whereas the second, despite more time-consuming, is advisable for topics which require understanding of complex interactions between multiple pieces of information.

Unlike other well-known methods that research has proven to be very useful too like interactive (online) tutorials, and visual screencasts with examples and demonstrations, the methods proposed here barely take extra time to the lecturer.

A last comment has also been provided on the fact that, in order to incentive the students to take preclass assignments seriously, they need to fairly contribute to the mark. These assignments are, therefore, both formative and summative in nature. However, the balance between both aspects must be kept carefully by the lecturer. In essence, the lecturer makes use of pre-class assignments because he/she wants his/her students to learn more (the formative assessment is more relevant in this sense), not because wishfully he/she wants to breakdown the final mark in more items. However, 
he needs to include the 'summative' bit in order to promote students' participation. For the student's perspective, however, the contrary applies. With a few exceptions, the students feels that he/she needs to do the assignments to not fall behind in the course mark, and if he/she learns something along the way that is complementary. As a matter of conclusion, after several years implementing the methods described in this paper in STEM subjects, a contribution of $5 \%$ to $20 \%$ has been found as the most appropriate.

\section{ACKNOWLEDGEMENTS}

We would like to acknowledge the help of one dedicated tutor of our Academic Practice Programme at the University of Reading, Mrs. Clare McCullagh from the Centre for Quality Support, for having provided us with timely and useful feedback on this initially coursework piece of assignment now turned into a conference paper.

\section{REFERENCES}

[1] G. Gibbs, "Twenty terrible reasons for lecturing," SCED Occasional Paper, 8 (Birmingham), 1981.

[2] D.A. Bligh, "What's the Use of Lectures?" (1st Ed.). Jossey-Bass, 2000.

[3] P. Elbow, "Embracing contraries: Explorations in learning and teaching," New York: Oxford University Press, 1986.

[4] J. Biggs \& C. Tang, "Teaching for Quality Learning at University Higher Education," (3rd Ed.) Maidenhead: Society for Research into Higher Education \& Open University Press, 2007.

[5] R.M. Felder \& R. Brent, "Teaching and learning STEM. A practical guide," Jossey-Bass (1st Ed.), 2016.

[6] W.J. McKeachie \& M. Svinicki, "McKeachie's teaching tips: Strategies, research, and theory for college and university teachers" (12th Ed.). Florence, KY: Cengage Learning, 2005.

[7] K.A. Smith, S.D. Sheppard, D.W. Johnson \& R.T. Johnson, "Pedagogies of engagement: Classroom-based practices," Journal of Engineering education, vol. 94, pp. 87-101, 2005.

[8] J. Bergmann, \& A. Sams, "Flip your classroom: reach every student in every class every day," Washington, DC: International Society for Technology in Education, 2012.

[9] R.M. Felder \& R. Brent, "Navigating the Bumpy Road to Student-centered Instruction," College Teaching, vol. 44, no.2, pp. 43, 1996.

[10] E.H. Hobson, "Getting students to read: Fourteen tips," (IDEA paper 40). Manhattan, KS: The IDEA Center, 2004. Retrieved on the $24^{\text {th }}$ November 2016 from: http://www.ideaedu.org/Portals/O/Uploads/Documents/IDEA\%20Papers/IDEA\%20Papers/Idea_ Paper_40.pdf

[11] R.M. Felder, "Sermons for grumpy campers," (Random thoughts series), Chemical Engineering Education, vol. 41, no. 3, pp. 183-184, 2007.

[12] S. Simkins \& M. Maier, "Just-in-time teaching: Across the disciplines, and across the academy". Sterling, VA: Stylus Publishing, 2009.

[13] M.J. Prince \& R.M. Felder, "Inductive teaching and learning methods: Definitions, comparisons and research bases," Journal of Engineering Education, vol. 95, no. 2, pp. 123-138, 2006.

[14] M.J. Prince \& R.M. Felder, "The many faces of inductive teaching and learning," Journal of college Science Teaching, vol. 36, no. 5, pp. 14-20, 2007.

[15] A. King, "From sage on the stage to guide on the side," College Teaching, vol. 41, no. 1, pp. 3035, 1993.

[16] M.J. Prince, "Does Active Learning Work? A Review of the Research," Journal of Engineering Education, vol. 93, no. 3, pp. 223, 2004. 
[17] G.W. Ellis, A. Rudnitsky \& B. Silverstein, "Using concept maps to enhance understanding in engineering education," International Journal of Engineering Education, vol. 20, no. 6, pp. 1012-1021, 2004. 